\title{
Blended Learning of Physics in the Context of the Professional Development of Teachers
}

\author{
https://doi.org/10.3991/ijet.v14i23.11084 \\ Lyubov Krasnova, Viktor Shurygin ${ }^{(凶)}$ \\ Kazan Federal University (Volga Region), Elabuga, Russian Federation \\ shuryginviktor@yahoo.com
}

\begin{abstract}
The electronization of education takes place integrally with the social-sector digitalization processes. Moreover, this phenomenon applies to both those who study and those who teach. Thus, a special place in the innovation-driven learning environment is occupied by the professional development courses for teachers. These courses are designed distinctive and technologybased, with the elements of a distance learning approach. Together they make up a special "blended" learning system, which implies a close relationship between conventional educational technologies and the distance learning tools. This article describes a study conducted at the Elabuga Institute of Kazan Federal University on the blended learning model applications. The study was carried out in 2016/2018 and involved 89 teachers of physics. The teacher-training course used there is built on the basis of a LMS Moodle software and the learning outcomes of teachers indicate the effectiveness of blended physics teacher training. The findings are relevant to both the educational institutions that are on the path towards modernized refresher training and the faculty staff as they serve an example of how new professional information may be perceived if the information technologies are involved.
\end{abstract}

Keywords - learning technologies; distance learning; e-learning; LMS Moodle, physics.

\section{$1 \quad$ Introduction}

Changes that occur in the education system, as well as new modifications made on the back of these changes, are a good reason for identifying new approaches and teaching modes in order to prepare teachers for solving a variety of arising problems [1]. In these circumstances, special attention should be paid to the advanced professional development of teachers [2]. At this point, refresher courses should be based on modern learning technologies. Integrated online (usually distance courses) and traditional learning are one of the models of modern education [3]. This model is known as blended learning.

In truth, there is no generally accepted classification of the specific blended learning models [1], [4]. The most common are Rotation models (Station Rotation, Lab 
Rotation, Individual Rotation, Flipped Classroom), Flex model, A La Carte model, Enriched Virtual model.

Despite the differences, all existing models of blended learning lean the following three pillars:

- Traditional direct face-to-face interaction between the participants of the leaching and learning process.

- Technology-mediated interaction.

- Self-teaching.

It is believed that the technology of blended learning combines formal and informal learning, face-to-face and online communication, guided activity and independent selection of a path towards personal goals and objectives [5], [6].

Blended learning is about teaching students how to make decisions, how to plan and organize their activities independently, how to handle the online learning platform, and how to search for, select and analyze the information [7]. The e-learning component of blended learning can be put into practice by all manner of tools [8], [9], including the social network, for example - the Facebook [10], [11]. In most cases, however, teachers tend to apply various learning management systems (LMSs). These systems are a complex of web-based software and hardware tools, teaching methods and technical measures [12]. Currently, there are lots of such systems in the world, for example - the BlackBoard, WebCT, Top-Class, Claroline, ILIAS, Desire2Learn, Moodle, etc. [13] They allow teachers to create interactive e-learning courses that contain all the necessary teaching and support aids, and tests [14]. The availability of such courses provides an opportunity to take a blended learning approach effectively, as a combination of traditional and distance e-learning [15].

Online learning platform, that is known as the Modular Object-Oriented Dynamic Learning Environment (Moodle) is widespread in Russia, as well as in many other countries. LMS Moodle has been effectively used in education for more than ten years. Both universities [16], [17] and schools handle the platform and benefit from it [18]. This system has become widespread over the years, in particular, in the field of teaching physics at various levels of education [19], [20].

Distance learning becomes more popular from day to day, significantly expanding the learning space [21] and allowing students to delve into university programs on a deeper level [22]. Computer-based technologies allow participants in the learning process to exchange information at any distance. Besides, such a learning mode has a number of advantages over traditional one, as it provides students the opportunity to learn at their own pace and within their own space [23]. Enhancing distance learning is a problem nowadays because teachers are not ready for such an experience, they lack IT competence and necessary skills to use computer-based online learning systems [24], [25]. In current settings, successes of distance learning is tied to how teachers view the process. Some often question the effectiveness of online education because of time factors and technical issues [26], [27]. We believe that adding some of the elements of distance learning into refresher courses for teachers will raise their trust with the said mode and give a boost to their IT competence development. 
Currently, it is beyond argument that various types of e-learning are good when it comes to education quality improvement [28]-[30]. However, we believe that this problem is little studied in the context of refreshercourses design for teachers. In particular, issues related to the optimal structure and content of e-courses, as well as to the course-specific methods of their application, remain relevant and open. At the same time, creating a comfortable e-learning environment for any course as a communication system with high degree of interactivity is a significant and important issue within the concept of blended learning. Thus, the purpose of this paper is to study how the features of blended learning application through a LMS Moodle can be put to design refresher courses for the physics teachers.

\section{Method}

\subsection{Participants}

The efficiency of blended refresher courses, designed for the physics teachers, was studied at the Elabuga Institute of the Kazan Federal University in 2016-2017 and in 2017-2018. The advanced course syllabus was designed for teachers leading physics courses under the programs for secondary general education.

The total number of course participants was 89 (28\% - male participants, $62 \%$ female participants). All of them were working as schoolteachers of physics. The average age of participants was 36 years. All respondents hold degrees in physics education and because of this the study eliminates professionally inadequate judgements. In addition, each respondent has at least 10 years of teaching experience, which contributes to the accuracy of conclusions regarding the adaptability of the suggested course to the school setting. Over the past 10 years, respondents have been following the uniform national standards. Therefore, the research sample is homogeneous and the professional motives of respondents may be considered similar.

All participants were informed about the project objectives and content, as well as about all the aspects of the research ethics. Participants gave written permission to use some of their personal data as research material (biographical derails, photos).

\subsection{Design}

The modular syllabus of blended refresher courses designed for the physics teachers contains the following blocks: modern educational standards, psycho-pedagogical basics of professional activity, contextual and procedural aspects of professional activity, and applied aspects of solving recent professional problems. These modules contain all necessary learning materials: course syllabus; teacher guides containing subject-specific teaching methodologies, current course guides, labs and tests. There is also an interactive glossary; teaching aids, electronic problem books; lists of recommended literature available in the University library, hyperlinks to electronic sources of information, electronic learning resources of other universities; discussion forums; text and video files containing lectures. 
In addition to the on-site lecture module, this course includes a distance e-learning module, designed in LMS Moodle. This system has proved to be quite effective in different countries [31]-[33], in particular, when it comes to applying a blended learning approach during physics assignments [19], [34], [35].

The distance learning module has a certain structure, containing an outline and a thematic part. It was designed to achieving a certain outcome while training teachers to work in modern learning environment. Thus, outline contains introductory videos, schedule, syllabus, short compendium, project topics, general teacher/student guidelines and a glossary. It also contains a list of related topics, a news forum and a discussion forum.

Each thematic part contains the following elements: the necessary theoretical material, hands-on material, various independent assignments, tests, and a list of recommended periodicals, as well as hyperlinks to electronic sources of information. The courses were tuned with traditional face-to-face modes of teaching and learning. The syllabus of these courses provided for a combination of different types of in-class learning, internships and independent activities. Thus, it implied that participants would bring the acquired experience into the real practice to solve the professionspecific problems.

\subsection{Research tools}

Various monitoring methods can be used in order to assess the quality of training: observation, swot analysis, polling, etc. We applied one of the most effective methods for assessing the quality of training - the polling. This method allows assessing the quality of the learning process, analyzing the received results, and drawing the corresponding conclusions. We applied the process approach to establish certain indicators and quality criteria, design the polling tools and select the proper methods for analyzing and presenting the results.

Monitoring indicators: opinions on the quality of the blended learning process, gathered through an opinion poll. The estimates were analyzed by means of a 10-point semantic differential scale, where " 0 " stands for the low quality and " 10 " - for the high quality.

All indicators (questions) are grouped into four blocks; each thereof contains three indicators (quality criteria).

Block 1. Information Content of the Course: relevance, practical focus and the structure.

Block 2. The Quality of E-Learning Resources integrated in the distance learning platform: ease of understanding, exhaustibility, and ease of use.

Block 3. Process Features: correspondence between the module content and the course purpose, application of active teaching methods, participant involvement in this course.

Block 4. The Quality of Online Learning Platform designed with LMS Moodle: interactivity level, interface user-friendliness, possibility to work with training and test modules. 
The poll was conducted after the final paper was defended using the LMS Moodle. The course participants were informed about the confidentiality of diagnostic results before the course. The polling data was processed with IBM SPSS Statistics 22.

\section{$3 \quad$ Results}

New potential opportunities for implementing the teacher refresher courses were determined with regard to the concept of blended learning, as such model allows organizing the teaching and learning process involving additional learning resources and technologies. Such model is also capable of bringing the learning process to a higher level - it can improve its quality, change the educational content, ensure the introduction of innovative learning technologies into the teaching and learning process.

We designed some refresher courses (108 hours) for the physics teachers with regard to a technology-based blended learning approach integrating the traditional faceto-face modules with the distance learning. They were implemented twice during the 2016-2018. The main purpose of the course was to upgrade the skills that teachers have for delivering the secondary education physics program on the back of changed requirements for organizing the modern learning process and gaining professional competencies in the field of learning process and lesson design using the innovation technologies.

Course objectives:

- Creating conditions for improving the professionalism of teachers, their professional competencies in designing, implementing and analyzing the professional activity in the context of education modernization

- Showing to course participants the insights into the methodology, structure, content and methods for organizing the modern learning process and designing lessons under new conditions

- Teaching the peculiarities of applying health-saving technologies in the teaching and learning process

- Shaping the teacher's professional culture in the field of ICT-rich environment.

Course units intended for online attendance were put into practical context by LMS Moodle. Our e-learning course is hosted on the University's e-learning platform and is available at any time. The LMS Moodle-based course communication capabilities enable teachers and supervisors to work with course participants under best possible conditions. The e-learning platform provides access to student profiles, allows them to handle a set of learning modules under the course program via remote access (taking tests, sending the results to the teacher, listening to webinars, etc.). The courses were tuned with traditional modes of teaching and learning. It should be noted that all learning materials are available in both Russian and English languages. Students have the opportunity to select the language by clicking the "Change language" icon.

The midpoint and final assessments are specific course units of highest-priority. Different types of assignments and tests are used for knowledge assessment. LMS Moodle has broad options for test design and application [36]. The system allows you 
to create various unique tests: traditional tests (tests with open-ended and closedended questions, matching tests, etc.) and more complex ones in structure and content. The latest version of LMS MOODLE allows you to create 32 types of tests. At the same time, course participants, who took the course on problem-solving methodology for problems of different complexity classes, not only participate in controlled assessment, but also gain experience in designing the assessment tasks. A specific test is randomly generated from the originally designed item bank. The course participants believe that the most interesting and insightful types of tests are the "Calculation", "Embedded answers" and "Essays" types. Thus, each option of the Calculation Test is generated with new numerical data from the given interval. Thus, even if several examinees receive the same task, it will contain different numerical data.

The Essays Test contains open-answer questions with the answer space is defined by size settings. The question can be represented as a text of a high-quality problem and as any media file, such as video or animated presentation. The answer is checked for correctness and graded manually by the teacher. This type of questions informs about how well the examinees understand the physical phenomenon. Such tasks can be used not only as a means of assessment, but also as a means of in-class consolidation of learnt material. They can be also used to form in course participants some skills of applying the gained knowledge to explain specific physical processes and phenomena.

The peculiarity of Embedded Answers Test is that it can include various types of questions, limited only by the originator's imagination (Figure 1). Such system was used when learning the physics problem-solving methods by physics branches and building the related skills.

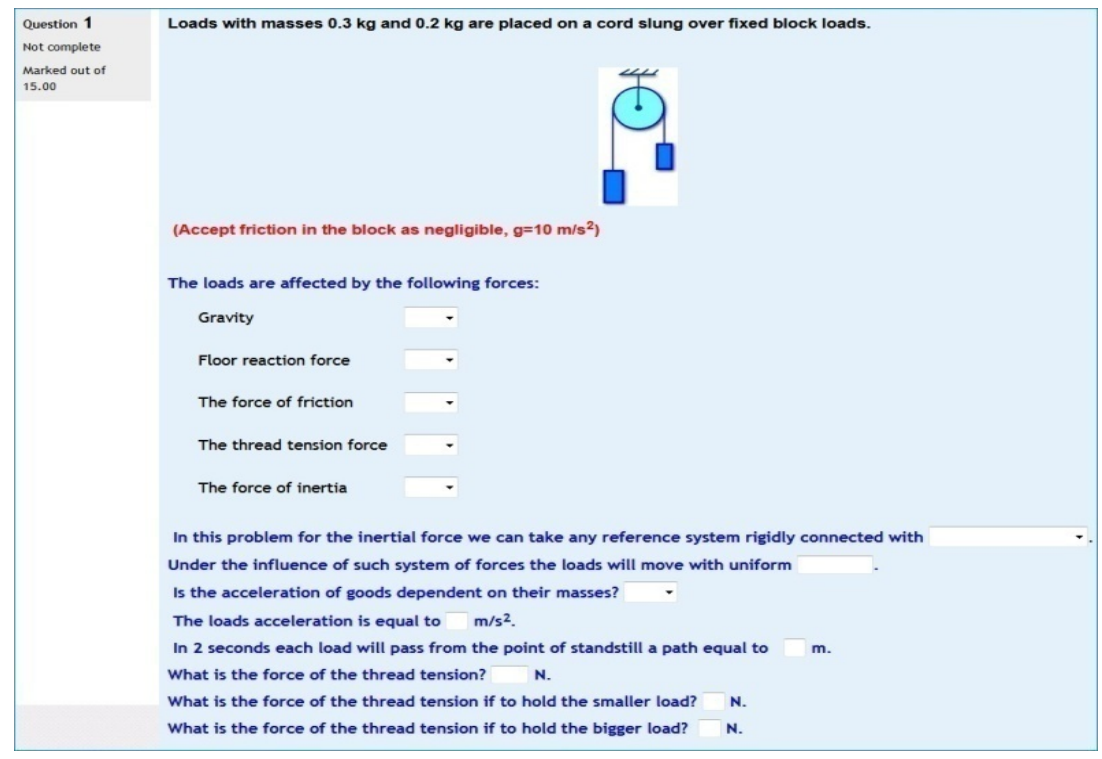

Fig. 1. Example of the Embedded Answers Test 
When it comes to the process of teaching teachers, it is necessary not only to teach them the basics of science and the case-specific teaching methods, but also to foster a common culture within them. The solution of this problem can be boosted by introducing some biographical details into the process that are often left aside during an in class assignment due to the lack of time. Details on the history of physics was built into the various elements of the online module. We designed a system containing various types of tests with some details on the history of physics included in them to assess the depth of gained knowledge (Figure 2).

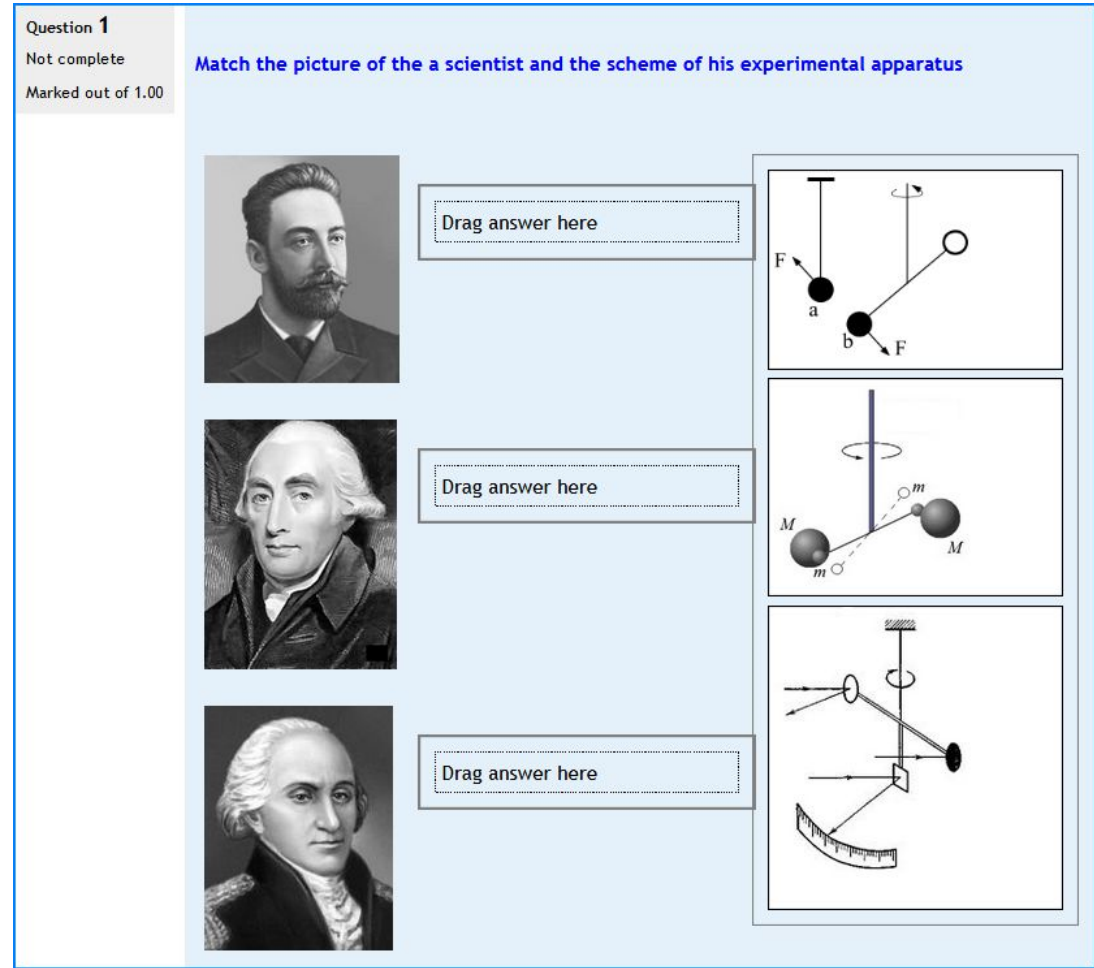

Fig. 2. Example of the Drag-and-Drop Matching Test

The refresher course culminates with a project defense, which is a kind of discussion platform for the course participants to exchange experience, as well as for innovative ideas and positive attitudes to further teaching activity to spark. The "poll" and a "questionnaire" are important components of the LMS Moodle when it comes to conducting pedagogical research and analyzing learning outcomes. The quality of blended learning was assessed under the process approach (EFQM excellence model). This model implies that the education quality issues are considered against the background of student need satisfaction, while the quality of training is ensured through the process management. These tools were used to carry out a participant poll at the final stage of training. Its purpose was to find out what opinions the course partici- 
pants have on the efficiency of blended refresher courses in general, and on the elearning in particular. In order to get an objective feedback, polling was conducted confidentially when the participants received their certificates. The polling involved 89 participants. Polling data were processed with IBM SPSS Statistics 22. The information on questionnaire indicators was collected by calculating moral expectation $\mathrm{m}$ and the standard square deviation $\mathrm{S}$ for each indicator. The results are presented in Figures 3 and 4.

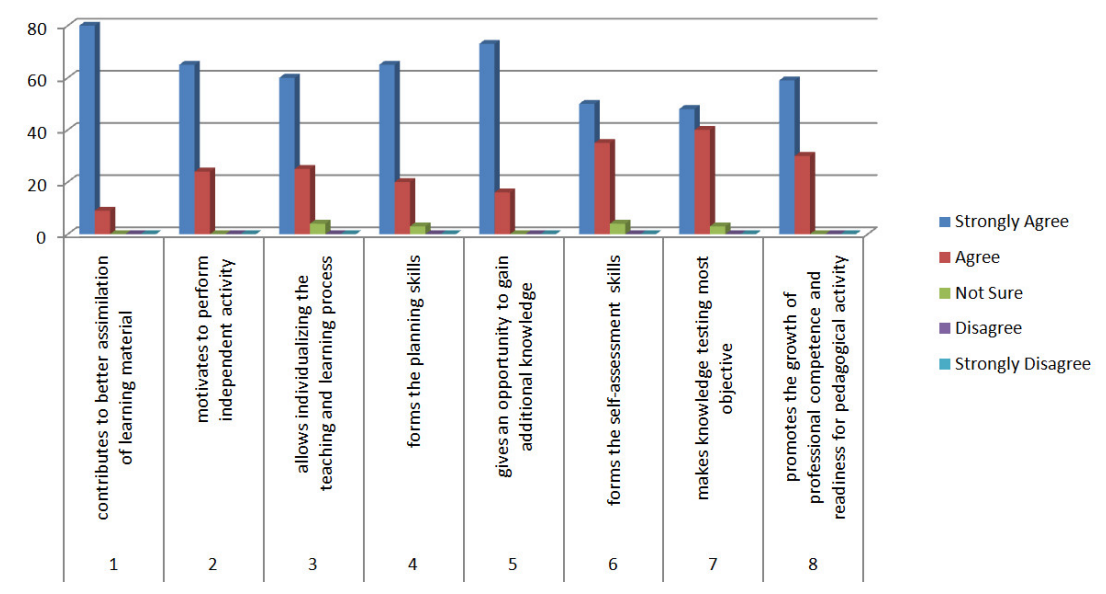

Fig. 3. General Polling Results 
Paper-Blended Learning of Physics in the Context of the Professional Development of...
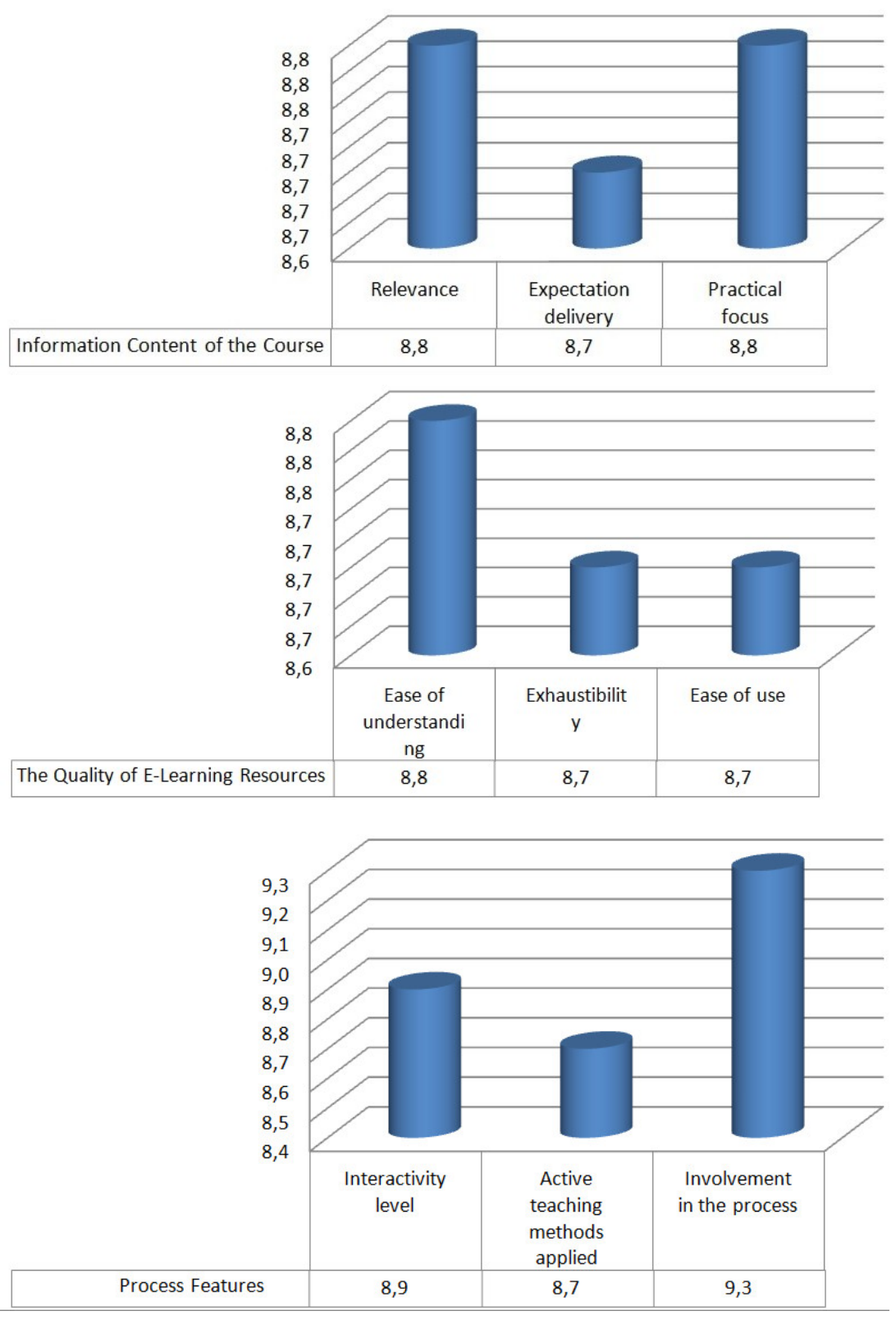


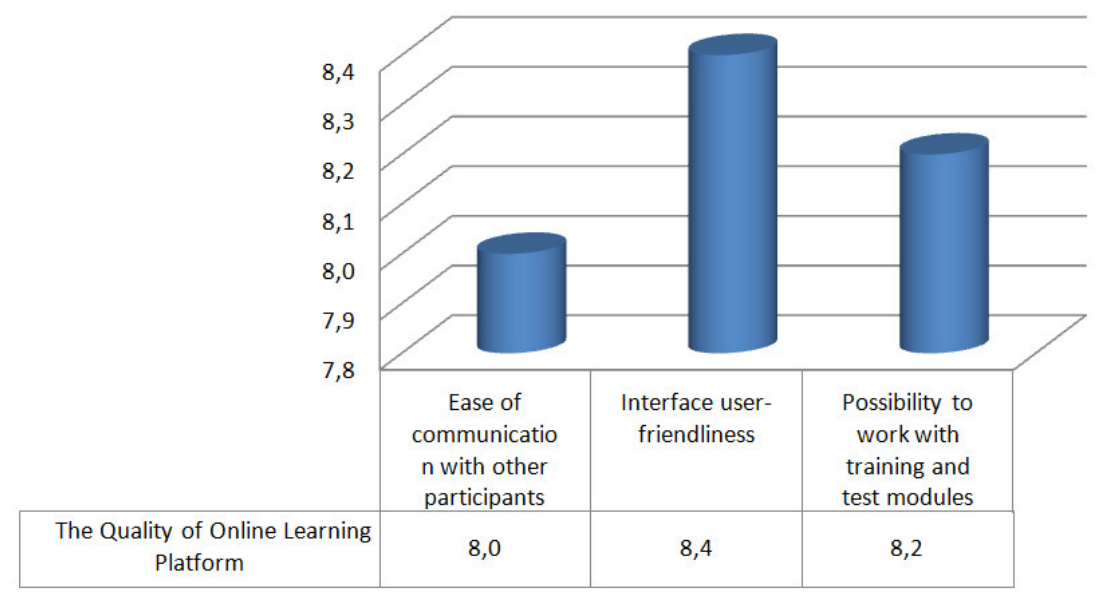

Fig. 4. Polling Results obtained with a Questionnaire

Based on polling results, we can conclude that the quality of blended refresher courses was assessed as high. In particular, course participants enjoyed the e-learning platform, gave credence to the learning materials of the course modules, appreciated their multi-dimensional focus and complementarity, and were pleased with the ease of navigation and compatibility options of the LMS Moodle. Besides, $79.3 \%$ of respondents agreed that the online course contributed to computer competency development. The findings show that the LMS Moodle platform is a good fit if your intent is to design refresher training courses for teachers of natural sciences, as it highly satisfies the needs of users (in this case, the respondent group). The course participants also pointed to the high professionalism of the teaching staff and supervisors. Thus, in modern environment, refresher courses are not only an opportunity to improve one's professional skills and competency, but also an important link between the school and university.

\section{Discussion}

One of the strengths that the LMS Moodle has is the communication opportunity [37]. The system supports the exchange of files of any format both between the teacher and the student, and between the students. The bulk email service allows anyone to inform all the course participants or individual groups about the current events promptly. The forum provides an opportunity to organize a discussion over the most hard-hitting topics. The chat room allows anyone to organize a discussion in real time.

At this stage, the Collaborative Case-Based Assessment becomes one of the most discussed issues. Collaboration allows developing both professional and communicative competence in students divided in small groups [38]. Thus, LMS Moodle has the following features that raise the interest of students in the subject, develop their skills and motivate to independent activity: high level of interactivity, multitude of material presentation, the possibility of modular content structuring and student-centered plan- 
ning, on-line documentation, comfort and confidentiality [39]. In this regard, a direct relationship is establishedbetween the LMS application and learning process efficiency [40].

It should also be noted that the course design is adapted to mobile devices. This allows using any modern gadget to handle the course [41]. A mobile phone has become an integral part of every-day life. It can be used for entertainment, communication, and for training. In the latter case, the phone is proven a powerful tool [42]. Another important aspect is related to the specific features of physics education, which implies laboratory training and the research work. The fact is that there are many experiments that cannot be performed in real laboratories because they are very dangerous, expensive, complex and time-consuming [34]. E-learning opens huge opportunities for the use of various kinds of virtual physics experiments [43], [44].

E-learning (LMS in particular) extends its boundaries beyond the universities to the colleges and schools [18], [45]. Those, who stand for VR in teaching and learning, prove that virtual environment is an excellent teaching tool [46]. At this point, the teacher's job is to put virtual technologies in the learning contexts. This imposes high requirements for the IT competence of a modern teacher. Part of the present learning modules are focused on the teacher's IT competence development and improvement with regard to modern innovation-driven trends in this field and to the peculiarities of their application in the teaching and learning process. Some of our results correlate with the observations made with the second-year students at the University of St. Andrews in Scotland. The online course that has been applied when teaching quantum mechanics allowed comparing the experimental and expected data on the back of a rapid data collection, as well as to explain such a difference. Our results are similar to the data obtained by the Technical University of Madrid, where most students had a positive experience of online testing. In addition, blended physics learning improves the learning outcomes significantly [47].

The obtained results inspire for further research aimed at improving the online refresher course for the physics teachers and methods of its application. Further research can be a more detailed insight into the efficiency of some course units tied with the methodology of teaching physics in schools.

\section{Conclusion}

Thus, this article presents the results from applying the blended refresher courses designed for the physics teachers. The online part of the course is realized through the e-learning modules originally designed with the LMS Moodle platform. A distinctive feature of their content is that it was designed in a way so that physics teachers could improve their competencies in terms of teaching methods, common values and culture. This was achieved, in particular, by including methodological and biographical materials to the course units.

Results display that blended form of education allows building case-specific vectors of training, expanding the range of educational opportunities by making the process more responsive and easy to engage in, and considering educational needs and 
abilities of participants. Blended learning strategies allow strengthening the existing skills and forming the new ones. Thereby, they create a multitasking environment, which is good and comfortable for those learning within it. Usable interface of the LMS Moodle platform enables an optimal bridge between knowledge delivery and interactive collaboration so that learning goal and objectives could be achieved, and professional qualities and competences formed.

The analysis of polling results allows concluding that blended learning has high but undeveloped potential in the context of teacher's professional development, his/her readiness to perform professional activities in modern environment. High level of satisfaction with the quality of blended learning and e-learning environment allows assuming that refresher courses are not only an opportunity for a teacher to improve one's professional skills and competences, but also an essential link between teachers and students (both at the level of skills and at the levels of knowledge acquisition techniques) [48]). This aspect is essential, given the correlation between a teacher's attitude towards information technology and the accumulation of knowledge by students, especially in the field of natural sciences [49].

The elements of blended learning expand the range of educational opportunities for students, who take these courses. They allow building individual learning paths, promoting the interaction between all the participants and forming the best possible qualities and competencies that a teacher should possess to perform successfully and effectively. It should also be noted that the above-mentioned advantages lay sufficient grounds for the LMS Moodle platform to be applied for this purpose, as the e-learning platform allows improving the IT competencies that are so much required. In this regard, the outlined experience of holding the blended refresher courses, designed for the physics teachers, integrating traditional face-to-face modules with the distance learning in the LMS Moodle platform can be useful to educational establishments implementing the teacher refresher courses.

According to the findings, LMS Moodle platform is ideally suited for the creation of refresher training courses for teachers of natural sciences, as it highly satisfies the needs of users (in this case, the respondent group). Raised issues require further discussion, especially issues like the optimal ratio of full-time (classroom) to online activities, a blended learning model considered suitable for investigating and solving problems in teaching physics and other disciplines, and further improvement of designed courses.

\section{$6 \quad$ Prospects and Potential}

The findings are relevant to both the educational institutions that are on the path towards modernized refresher training and the faculty staff as they serve an example of how new professional information may be perceived if the information technologies are involved. Further studies will allow developing an effective framework of blended refresher training for other teachers, which could by applied by organizations as a core model. The present results confirm the global trend in ICT and education, which can be described as the use of ICTs for learning regardless of age. This opened 
a door to a new area of research - educational software adaptive to the cognitive needs of adults.

\section{$7 \quad$ References}

[1] M. J. Kintu, C. Zhu, and E. Kagambe, "Blended learning effectiveness: the relationship between student characteristics, design features and outcomes", International Journal of Educational Technology in Higher Education, vol. 14, no. 1, p. 7, 2017. https://doi.org/10. 1186/s41239-017-0043-4

[2] F. Gomez Zaccarelli, A. K. Schindler, H. Borko, and J. Osborne, "Learning from professional development: a case study of the challenges of enacting productive science discourse in the classroom", Professional Development in Education, pp. 1-17, 2018. https://doi.org/10.1080/19415257.2017.1423368

[3] W. J. Fraser, 'Science Teacher Educators' Engagement with Pedagogical Content Knowledge and Scientific Inquiry in Predominantly Paper-Based Distance Learning Programs", Turkish Online Journal of Distance Education, vol. 18, no. 4, pp. 35-51, 2017. https://doi.org/10.17718/tojde.340375

[4] M. Burns, "Distance Education for Teacher Training: Modes, Models and Methods", 2011. [Online].Available: http://idd.edc.org/sites/idd.edc.org/files/DE\%20Book-final.pdf [Accessed Jun. 15, 2019]

[5] A. Rosett, and F. Vaughan, Blended learning. CEOEpicGroupplc, 52 OldSteine, Brighton, 2003.

[6] M. G. Moore, Handbook of Distance Education. New York, NY: Routledg, (3rd ed., 2012.

[7] J. L. Moore, C. Dickson-Deane, and K. Galyen, "e-Learning, online learning, and distance learning environments: Are they the same?". The Internet and Higher Education, vol. 14, no. 2, pp. 129-135, 2011. https://doi.org/10.1016/j.iheduc.2010.10.001

[8] M. C. Linn, Internet environments for science education. Routledge, 2013.

[9] W. G. Bowen, M. M. Chingos, K. A. Lack, and T. I. Nygren, "Interactive learning online at public universities: Evidence from a six campus randomized trial", Journal of Policy Analysis and Management, vol. 33, no. 1, pp. 94-111, 2014. https://doi.org/10.1002/pam. $\underline{21728}$

[10] H. Meishar-Tal, G. Kurtz, and E. Pieterse, "Facebook groups as LMS: A case study”, The International Review of Research in Open and Distributed Learning, vol. 13, no. 4, pp. 3348, 2012.

[11] R. A. Jones, and S. A. Bogle, "An Investigation of the Use of Facebook Groups as a Learning Management System to Improve Undergraduate Performance", In Proceedings of the World Congress on Engineering and Computer Science, vol. 1, 2017.

[12] G. Naveh, D. Tubin, and N. Pliskin, "Student LMS use and satisfaction in academic institutions: The organizational perspective", The Internet and Higher Education, vol. 13, no. 3, pp. 127-133, 2010. https://doi.org/10.1016/j.iheduc.2010.02.004

[13] J. L. Green, G. Camilli, and P. B. Elmore, Handbook of complementary methods in education research, Routledge, 2012.

[14] T. Almarabeh, "The University of Jordan E-Learning Platform: State, Students' Acceptance and Challenges", Journal of Software Engineering and Applications, vol. 7, pp. 999-1007, 2014. https://doi.org/10.4236/jsea.2014.712087

[15] R. Cerezo, M. Sanchez-Santillan, M. P. Paule-Ruiz, and J. C. Nunez, "Students' LMS interaction patterns and their relationship with achievement: A case study in higher educa- 
tion”, Computers \& Education, vol. 96, pp. 42-54, 2016. https://doi.org/10.1016/j.comp edu.2016.02.006

[16] C. Costa, H. Alvelos, and L. Teixeira, "The use of Moodle e-learning platform: A study in a Portuguese university”, Procedia Technology, vol. 5, pp. 334-343, 2012. https://doi.org/ 10.1016/i.protcy.2012.09.037

[17] T. Escobar-Rodriguez, and P. Monge-Lozano, "The acceptance of Moodle technology by business administration students", Computers and Education, vol. 58, no. 4, pp. 10851093, 2012. https://doi.org/10.1016/i.compedu.2011.11.012

[18] S. Psycharis, G. Chalatzoglidis, and M. Kalogiannakis, "Moodle as a learning environment in promoting conceptual understanding for secondary school students", Eurasia Journal of Mathematics, Science \& Technology Education, vol. 9, no. 1, pp. 11-21, 2013. https://doi. org/10.12973/eurasia.2013.912a

[19] F. Ekici, I. Kara, and E. Ekici, "The primary student teachers' views about a blended learning application in a basic physics course", The Turkish Online Journal of Distance Education, vol. 13, no. 2, pp. 291-310, 2012).

[20] M. Basitere, and E. Ivala, "Evaluation of an adaptive learning technology in a first-year extended curriculum programme physics course", South African Computer Journal, vol. 29, no. 3, pp. 1-15, 2017. https://doi.org/10.18489/sacj.v29i3.476

[21] J. Beese, "Expanding learning opportunities for high school students with distance learning”, American Journal of Distance Education, vol. 28, no. 4, pp. 292-306, 2014. https://doi.org/10.1080/08923647.2014.959343

[22] M. Aktaruzzaman, and M. Plunkett, "An Innovative Approach toward a Comprehensive Distance Education Framework for a Developing Country", American Journal of Distance Education, vol. 30, no. 4, pp. 211-224, 2016. https://doi.org/10.1080/08923647.2016.122 $\underline{7098}$

[23] B. Thoms, and E. Eryilmaz, "How media choice affects learner interactions in distance learning classes", Computers \& Education, vol. 75, pp. 112-126, 2014. https://doi.org/10. 1016/j.compedu.2014.02.002

[24] A. Badia, J. Meneses, C. Sigalés, and S. Fàbregues, "Factors affecting school teachers' perceptions of the instructional benefits of digital technology", Procedia-Social and Behavioral Sciences, vol. 141, pp. 357-362, 2014. https://doi.org/10.1016/j.sbspro.2014.05.063

[25] I. A. Leontyeva, "Modern distance learning technologies in higher education: Introduction problems", Eurasia Journal of Mathematics, Science and Technology Education, vol. 14, no. 10, pp. 1-8, 2018. https://doi.org/10.29333/ejmste/92284

[26] T. Anderson, and J. Dron, "Three generations of distance education pedagogy", The International Review of Research in Open and Distributed Learning, vol. 12, no. 3, pp. 80-97, 2011. https://doi.org/10.19173/irrodl.v12i3.890

[27] M. L. Hung, "Teacher readiness for online learning: Scale development and teacher perceptions", Computers \& Education, vol. 94, pp. 120-133, 2016. https://doi.org/10.1016/j. compedu.2015.11.012

[28] T. Nguyen, "The effectiveness of online learning: Beyond no significant difference and future horizons", MERLOT Journal of Online Learning and Teaching, vol. 11, no. 2, pp. 309-319, 2015.

[29] L. A. Krasnova, and V. Y. Shurygin, "Development of teachers' information competency in higher education institution", Astra Salvensis, vol. 5, no. 10, pp. 307-317, 2017.

[30] A. Sheshasaayee, M. N. Bee, "E-learning: Mode to Improve the Quality of Educational System", Smart Computing and Informatics. Springer, Singapore, 2018, pp. 559-566.

[31] G. M. Amandu, J. K. Muliira, and C. F. Fronda, "Using Moodlee-learning platform to foster student self-directed learning: experiences with utilization of the software in under- 
graduate nursing courses in a Middle Eastern university". Procedia - Social and Behavioral Sciences, vol. 93, pp. 667-683, 2013. https://doi.org/10.1016/j.sbspro.2013.09.260

[32] D. Benta, G. Bologa, and I. Dzitac, "E-learning platforms in higher education. Case study", Procedia Computer Science, vol. 31, pp. 1170-1176, 2014. https://doi.org/10.1016/ i.procs.2014.05.373

[33] E. Costello, "Opening up to open source: Looking at how Moodle was adopted in higher education, Open Learning”, The Journal of Open, Distance and e-Learning, vol. 28, no. 3, pp. 187-200, 2013. https://doi.org/10.1080/02680513.2013.856289

[34] A. Drigas, and M. T. L. Kontopoulou, "ICTs based Physics Learning", International Journal of Engineering Pedagogy, vol. 6, no. 3, pp. 53-9, 2016. https://doi.org/10.3991/ijep.v6 $\underline{i 3.5899}$

[35] V. Y. Shurygin, and F. M. Sabirova, "Particularities of blended learning implementation in teaching physics by means of LMS Moodle", Espacios, vol. 38, no. 40, pp. 39, 2017.

[36] V. Y. Shurygin, and L. A. Krasnova, "Electronic Learning Courses as a Means to Activate Students' Independent Work in Studying Physics", International Journal of Environmental and Science Education, vol. 11, no. 8, pp. 1743-1751, 2016.

[37] D. D. Essel, and O. A. Wilson, "Factors Affecting University Students' Use of Moodle: An Empirical Study Based on TAM", International Journal of Information and Communication Technology Education, vol. 13, no. 1, pp. 14-26, 2017. https://doi.org/10.4018/ijicte.2 $\underline{017010102}$

[38] B. Means, Y. Toyama, R. Murphy, M. Bakia, and K. Jones, "Evaluation of evidencedbased practices in online learning: a Meta-analysis and review of online learning studies", U.S. Department of Education, 2010. [Online]. Available: https://www2.ed.gov/rschstat/ eval/tech/evidence-based-practices/finalreport.pdf [Accessed Jun. 15, 2019].

[39] C. Limongelli, F. Sciarrone, and G. Vaste, "Personalized e-learning in Moodle: the Moodle_LS System", Journal of e-Learning and Knowledge Society, vol. 7, no. 1, pp. 49-58, 2011 .

[40] I. Mwalumbwe, and J. S. Mtebe, "Using Learning Analytics to Predict Students' Performance in Moodle Learning Management System: A Case of Mbeya University of Science and Technology", The Electronic Journal of Information Systems in Developing Countries, vol. 79, no. 1, pp. 1-13, 2017. https://doi.org/10.1002/j.1681-4835.2017.tb00577.x

[41] S. V. Titova, and T. Talmo, "Mobile voting systems for creating collaboration environment and get-ting immediate feedback: a new curriculum model of the university lecture", International Journal of Mobile and Blended Learning, vol. 6, no. 8, pp. 19-26, 2014. https://doi.org/10.4018/ijmbl.2014070102

[42] St. Papadakis, M. Kalogiannakis, E. Sifaki, and N. Vidakis, "Evaluating Moodle use via Smart Mobile Phones. A case study in a Greek University", EAI (European Alliance for Innovation) Endorsed Transactions on Creative Technologies, vol. 5, no. 16, pp. e1, 1-9, 2018. https://doi.org/10.4108/eai.10-4-2018.156382

[43] S. Grober, B. Eckert, and H. J. Jodl, "A New Medium for Physics Teaching: Results of a Worldwide Study of Remotely Controlled Laboratories (RCLs)", European Journal of Physics, vol. 35, no. 1, pp. 018001, 2013. https://doi.org/10.1088/0143-0807/35/1/018001

[44] G. E. Murakami, D. Hirata, M. A. A. Monteiro, D. M. Pinheiro, and J. S. E. Germano, "Proposal of a Learning Management System for Physics Education with the Inclusion of WebLab and Assessment of its Application", Journal of Environmental Science and Engineering, B 6, pp. 101-113, 2017. https://doi.org/10.17265/2162-5263/2017.02.005

[45] K. Udaya Sri, and T. V. Vamsi Krishna, "E-Learning: Technological Development inTeaching for school kids", International Journal of Computer Science and Information Technologies, vol. 5, no. 5, pp. 6124-6126, 2014. 
[46] K.M. Kapp, and T. O'Driscoll, Learning in 3D: Adding a New Dimension to Enterprise Learning and Collaboration. Published by Pfeiffer. An Imprint of Wiley, 2010.

[47] A. Kohnle, C. Baily, C. Hooley, and B. Torrance, "Optimization of simulations and activities for a new introductory quantum mechanics curriculum", arXiv preprint arXiv:1307.1483, 2013. https://doi.org/10.1119/perc.2013.pr.040

[48] S. Papadakis, "Evaluating pre-service teachers' acceptance of mobile devices with regards to their age and gender: a case study in Greece", International Journal of Mobile Learning and Organisation, vol. 2, no. 4, pp. 336-352, 2018. https://doi.org/10.1504/ijmlo.2018.1001 $\underline{3372}$

[49] M. Kalogiannakis, \& S. Papadakis, "Evaluating pre-service kindergarten teachers' intention to adopt and use tablets into teaching practice for natural sciences", Int. J. Mobile Learning and Organisation, vol. 13, no. 1, pp. 113-127, 2019. https://doi.org/10.1504/ijml $\underline{0.2019 .10016617}$

\section{Authors}

Lyubov Krasnova \& Viktor Shurygin (vjshurygin@kpfu.ru) work in Elabuga Institute of Kazan Federal University (Volga Region) Russian Federation.

Article submitted 2019-06-21. Resubmitted 2019-08-08. Final acceptance 2019-08-10. Final version published as submitted by the authors. 